\title{
Phytochemical analysis, total flavonoid, total phenolic contents and ferric reducing power of extracts from leaves and stem bark of Buddleja salviifolia
}

\author{
${ }^{1}$ Matamane, R.P., ${ }^{2}$ Magama, S., ${ }^{1}$ Pillai, M.K. and ${ }^{2}$ Mekbib, S.B. \\ ${ }^{1}$ Department of Chemistry and Chemical Technology, Faculty of Science and Technology, National \\ University of Lesotho, Roma Campus, P.O. Roma 180, Kingdom of Lesotho, Southern Africa \\ ${ }^{2}$ Department of Biology, Faculty of Science and Technology, National University of Lesotho, Roma Campus, \\ P.O. Roma 180, Kingdom of Lesotho, Southern Africa
}

\begin{abstract}
Article history:
Received: 11 September 2020

Received in revised form: 16

October 2020

Accepted: 29 October 2020

Available Online: 21 March

2021

Keywords:

Buddleja salviifolia,

Scrophulariaceae,

Total flavonoid contents

(TFC),

Total phenolic contents

(TPC),

Ferric reducing power
\end{abstract}

\begin{abstract}
Chloroform, ethyl acetate and methanolic extracts from leaves and stem bark of Buddleja salviifolia were prepared. The phytochemical profiles, total flavonoid contents (TFC), total phenolic contents (TPC) and ferric reducing power of these extracts were studied. The presence of alkaloids, tannins, phlobatannins, saponins, sterols, flavonoids, coumarins, phenolics, terpenoids, quinones and reducing sugars were identified from these extracts. The TFC of these extracts was found to be in the range of $11.36 \pm 0.98$ to $30.76 \pm 1.15 \mathrm{mg} \mathrm{QE} / \mathrm{g} \mathrm{DW}$, respectively. The TPC of these extracts was found to be in the range of $175.00 \pm 0.41$ to $465.27 \pm 2.65 \mathrm{mg} \mathrm{GAE} / \mathrm{g} \mathrm{DW}$, respectively. Additionally, these extracts showed a weak to moderate ferric reducing power compared to ascorbic acid. $B$. salviifolia finds therapeutic applications in traditional medicine. Further studies are required to commercialize products from this plant.
\end{abstract}

DOI:

https://doi.org/10.26656/fr.2017.5(2).505

\section{Introduction}

Buddleja salviifolia belongs to the Scrophulariaceae family of the Buddleja genus (Van Wyk and Van Wyk, 1997; Ream, 2006; Tank et al., 2006; Van Laere et al., 2011). B. salviifolia is also known by other names such as sailehout, sagewood, wildsaile and lelothoane (Van Wyk and Van Wyk, 1997; Kose et al., 2015). B. salviifolia is a semi-evergreen shrub (Ream, 2006) or trees of 3-8 m height (Drummond, 1981) and is widely distributed in the Southern Africa (Palmer, 1997). B. salviifolia finds therapeutic applications in the traditional medicine in the African continent. Particularly, the leaves of $B$. salviifolia possess most of the therapeutic potentials and have been used to treat TB, herpes, syphilis, cervical cancer, complications associated with pregnancy, coughs, colic, constipation, neurodegenerative diseases, eye infections and to relieve nausea (Pendota et al., 2013; Kose et al., 2015). The antimicrobial and DPPH radical scavenging activities of various extracts from leaves and stem bark of $B$. salviifolia have previously been reported (Matamane et al., 2019; Pillai et al., 2019). The present study aimed to analyse the phytochemical profiles, total flavonoid contents (TFC), total phenolic contents (TPC) and ferric reducing power of chloroform, ethyl acetate and methanolic extracts from leaves and stem bark of $B$. salviifolia species collected from the Kingdom of Lesotho, Southern Africa. This is the first report of this kind from the B. salviifolia and particularly, the species gathered from the Kingdom of Lesotho.

\section{Materials and methods}

\subsection{Chemicals and Reagents}

AR grades $(99.5 \%)$ of chloroform, ethyl acetate, methanol, benzene, quercetin, gallic acid and trichloroacetic acid were all purchased from Sigma Aldrich. Benedict's reagent, sodium hydroxide, hydrochloric acid and sulphuric acid were purchased from Minema Chemicals. Potassium ferricyanide, ferric chloride, sodium dihydrogen phosphate, magnesium powder, ascorbic acid, trisodium phosphate and potassium mercuric iodide were purchased from Prestige Laboratory Supplies.

\subsection{Plant materials}

The leaves and stem bark of $B$. salviifolia were collected in August 2018 at the National University of Lesotho, Roma campus. Voucher specimens for leaves 
(Matamane/BSLS/2018) and stem bark (Matamane/ $\mathrm{BSSB} / 2018$ ) were preserved in the Organic Research Laboratory, Department of Chemistry and Chemical Technology, National University of Lesotho, Roma Campus, Maseru, Lesotho.

\subsection{Processing of materials}

The leaves were allowed to air-dry at room temperature for two weeks and then ground into powder $(523.86 \mathrm{~g})$ using a laboratory blender (Waring Blender, Blender 80119, Model HGB2WT93, 240V AC, 3.5 AMPs, Laboratory and Analytical Supplies). The chopped stem bark was allowed to air-dry for two weeks and then ground into powder (760.46 g) using the same blender.

\subsection{Preparation of extracts}

A mass of $98.88 \mathrm{~g}$ of powdered leaves was macerated with $500 \mathrm{~mL}$ of chloroform for three days with occasional shaking. The resulting solution was filtered using a vacuum filter (ATB, Model: $284965-\mathrm{H}$, Power: 230 v $3.0 \mathrm{~A}, 1320 / \mathrm{min}, 50 \mathrm{~Hz}$ ) and the extract was concentrated in vacuo. The concentrated extract was then transferred to a pre-weighted clean and dry beaker. The procedure was replicated two times. Finally, the sample was refluxed with chloroform for $10 \mathrm{hrs}$ and the resulting solution was concentrated in vacuo. A mass of $7.48 \mathrm{~g}$ of combined chloroform extract was obtained. Similarly, 8.13 and $14.61 \mathrm{~g}$ of ethyl acetate and methanolic extracts were obtained, respectively from 100.23 and $175.45 \mathrm{~g}$ of powdered leaves. Using the similar extraction procedure, $1.07,2.18$ and $8.86 \mathrm{~g}$ of chloroform, ethyl acetate and methanolic extracts were obtained, respectively from 200.09, 200.01, 202.53 and $157.82 \mathrm{~g}$ of powdered stem bark.

\subsection{Phytochemical analysis}

Chloroform, ethyl acetate and methanolic extracts thus obtained from the leaves and stem bark of $B$. salviifolia were screened for their phytochemicals such as alkaloids, tannins, phlobatannins, saponins, sterols, flavonoids, coumarins, phenolics, terpenoids, quinones and reducing sugars using the methods described in the literature (Trease and Evans, 1984; Trease and Evans, 2002; Tiwari et al., 2011; Saeed et al., 2012; Soni and Sheetal, 2013; Nwaoguikpe et al., 2014; Pandey and Tripathi, 2014; Uddin et al., 2014).

\subsubsection{Detection of alkaloids}

A mass of $5.0 \mathrm{mg}$ of each extract was dissolved in $2.0 \mathrm{~mL}$ of distilled water separately and then three drops of Wagner's reagent was added. The formation of a reddish-brown precipitate indicates the presence of alkaloids.

\subsubsection{Detection of phenolics}

A mass of $0.5 \mathrm{~g}$ of each extract was dissolved in 1.0 $\mathrm{mL}$ of distilled water separately and was heated in a water bath at $95^{\circ} \mathrm{C}$ for 30 mins. The resulting mixture was filtered and $3.0 \mathrm{~mL}$ of $5 \%(\mathrm{w} / \mathrm{v})$ of ferric chloride was added to the filtrate followed by the addition of 1.0 $\mathrm{mL}$ of $1 \%(\mathrm{w} / \mathrm{v})$ potassium ferricyanide. A formation of green colouration indicates the presence of simple phenols and the blue colouration indicates the presence of polyphenols.

\subsubsection{Detection terpenoids}

A volume of $0.5 \mathrm{~mL}$ of distilled was added to $0.25 \mathrm{~g}$ of each extract separately and then $1.0 \mathrm{~mL}$ of chloroform was added with vigorous shaking and swirling. A formation of reddish-brown colouration on the interface upon the addition of $3.0 \mathrm{~mL}$ of concentrated sulphuric acid to the mixture indicates the presence of terpenoids.

\subsubsection{Detection of flavonoids}

A mass of $0.50 \mathrm{~g}$ of each extract was dissolved in 2 $\mathrm{mL}$ of methanol and heated in a water bath separately. A small amount of magnesium powder was added to the mixture and few drops of concentrated hydrochloric acid were added thereafter. A formation of dark brown colouration which gradually shades to deep red or pink colouration indicates the presence of flavonoids.

\subsubsection{Detection of sterols}

A mass of $0.3 \mathrm{~g}$ of each extract was dissolved in 2.0 $\mathrm{mL}$ of chloroform separately and then filtered off. A volume of $1.0 \mathrm{~mL}$ of concentrated sulphuric acid was added to each filtrate. A formation of two phases of which the chloroform phase turns red indicates the presence of sterols.

\subsubsection{Detection of saponins}

A volume of $2.0 \mathrm{~mL}$ of distilled water was added to $0.1 \mathrm{~g}$ of each extract separately and the contents were agitated in a test tube for 15 mins. A formation of a $1 \mathrm{~cm}$ layer of foam indicates the presence of saponins.

\subsubsection{Detection of tannins}

A mass of $0.2 \mathrm{~g}$ of each extract was dissolved in 2.0 $\mathrm{mL}$ of distilled water separately and heated in a water bath at $95^{\circ} \mathrm{C}$. Upon filtration, few drops of concentrated sulphuric acid were added to each filtrate followed by the addition of a few drops of $5 \%(\mathrm{w} / \mathrm{v})$ ferric chloride. A deposition of blue, black, green or blue-green precipitate indicates the presence of tannins. 


\subsubsection{Detection of phlobatannins}

A mass of $0.1 \mathrm{~g}$ of each extract was boiled in $3.0 \mathrm{~mL}$ of $1 \%$ aqueous hydrochloric acid separately. A formation of a red precipitate indicates the presence of phlobatannins.

\subsubsection{Detection of quinones}

A mass of $0.25 \mathrm{~g}$ of each extract was dissolved in 0.5 $\mathrm{mL}$ of distilled water separately and then $1.5 \mathrm{~mL}$ of concentrated hydrochloric acid was added to it. A deposition of green or white precipitate indicates the presence of quinones.

\subsubsection{Detection of reducing sugars}

A mass of $0.1 \mathrm{~g}$ of each extract was dissolved in 2.5 $\mathrm{mL}$ of distilled water separately. A volume of $2.0 \mathrm{~mL}$ of the extract solution was mixed with $2.0 \mathrm{~mL}$ of Benedict's solution. Each of these mixed contents was heated in a boiling water bath at $95^{\circ} \mathrm{C}$ for 5 mins or until there was an observable colour change. A formation of brick-red colouration indicates the presence of reducing sugars.

\subsubsection{Detection of coumarins}

A mass of $0.3 \mathrm{~g}$ of each extract was dissolved in 1.0 $\mathrm{mL}$ of distilled water separately and then $1.0 \mathrm{~mL}$ of $10 \%$ $(\mathrm{w} / \mathrm{v})$ sodium hydroxide and $1.0 \mathrm{~mL}$ of chloroform were added. A formation of yellow colour indicates the presence of coumarins.

\subsection{Determination of total flavonoid contents (TFC)}

The TFC of each of these six extracts was evaluated separately using the aluminum chloride calorimetric method as described in the literature (Joshi et al., 2019). The results were calculated based on a calibration curve plotted using quercetin. A stock solution of quercetin was prepared by dissolving $25 \mathrm{mg}$ of quercetin in $1.0 \mathrm{~mL}$ of methanol and serial dilutions of 25, 20, 15, 10 and 5 $\mu \mathrm{g} / \mathrm{mL}$ were prepared from the stock solution. A solution of $10 \mathrm{~mL}$ of each extract in methanol at a concentration of $1000 \mu \mathrm{g} / \mathrm{mL}$ was prepared separately. Aliquots of 3.0 $\mathrm{mL}$ of each extract or quercetin were mixed separately with $2 \%(\mathrm{w} / \mathrm{v})$ aluminum chloride in clean and ovendried test tubes. The experiment was performed in triplicates and the contents were incubated at room temperature for 15 mins. The absorbance was measured at $420 \mathrm{~nm}$ using MRS Spectro UV-11 spectrophotometer. The total flavonoid contents of each of these extracts were estimated from the quercetin calibration plot and are expressed as milligrams of quercetin equivalents per gram of extract dry weight (mg QE/g DW).

\subsection{Determination of phenolic contents (TPC)}

The TPC of each of these six extracts was determined separately using Folin-Ciocalteau assay (Kokate, 1994) with slight modifications. The results were calculated based on a calibration curve plotted using gallic acid. Briefly, $1000 \mu \mathrm{g} / \mathrm{mL}$ of stock solution of gallic acid was prepared by dissolving $10.0 \mathrm{mg}$ of gallic acid in $10 \mathrm{~mL}$ of methanol. Two-fold serial dilutions of 1000 to $15.625 \mu \mathrm{g} / \mathrm{mL}$ were prepared from the stock solution. A solution of $10 \mathrm{~mL}$ of each extract in methanol at a concentration of $1000 \mu \mathrm{g} / \mathrm{mL}$ was prepared separately. Aliquots of $2.0 \mathrm{~mL}$ of each extract or gallic acid solution were mixed separately with $1.0 \mathrm{~mL}$ of $1 \%$ $(\mathrm{v} / \mathrm{v})$ Folin-Ciocalteau reagent in clean and oven-dried test tubes. The reaction mixture was allowed to stand for 4 mins and then $1.0 \mathrm{~mL}$ of $0.7 \mathrm{M}$ sodium carbonate was added. The content was shaken vigorously for $15 \mathrm{~s}$ then incubated in the dark for 25 mins at room temperature with occasional agitation. The experiment was performed in triplicates. The absorbance of the reaction mixture was measured at $765 \mathrm{~nm}$ using MRS Spectro UV-11 spectrophotometer. The total phenolic content of each extract was estimated from the gallic acid calibration plot and are expressed as milligrams of gallic acid equivalents per gram of extract dry weight (mg GAE/g DW).

\subsection{Evaluation of ferric reducing power}

The ferric reducing power of these six extracts was determined using a method described in literature (Fejes et al., 2000) with slight modification. The ability of an extract to transform $\mathrm{Fe}$ (III) to Fe (II) has been termed as its ferric reducing power (Fejes et al., 2000; Saeed et al., 2012). The formation of Prussian blue colour indicates the transformation and the measure of absorbance at 700 $\mathrm{nm}$ indicates its ferric reducing power (Saeed et al., 2012). Briefly, a stock solution of $0.2 \mathrm{mg}$ of each extract in $1 \mathrm{~mL}$ of methanol was prepared, separately. Two-fold serial dilutions of 200 to $0 \mu \mathrm{g} / \mathrm{mL}$ were prepared. The 0 $\mu \mathrm{g} / \mathrm{mL}$ solution served as negative control while ascorbic acid served as a positive control. Aliquots of $2.0 \mathrm{~mL}$ of each extract at various concentrations were mixed with $2.0 \mathrm{~mL}$ of $0.2 \mathrm{M}$ phosphate buffer ( $\mathrm{pH} 6.6), 2.0 \mathrm{~mL}$ of $0.01 \%(\mathrm{w} / \mathrm{v})$ potassium ferricyanide solution and the mixture was separately incubated at $50^{\circ} \mathrm{C}$. A volume of $2.0 \mathrm{~mL}$ of $0.1 \%(\mathrm{w} / \mathrm{v})$ trichloroacetic acid was added to the mixture and the content was centrifuged at $3000 \mathrm{rpm}$ for 10 mins. The upper layer was collected thereafter and aliquots of $2.0 \mathrm{~mL}$ of the supernatant liquid were mixed further with $0.4 \mathrm{~mL}$ of $0.1 \%(\mathrm{w} / \mathrm{v})$ freshly prepared ferric chloride solution and $2.0 \mathrm{~mL}$ of distilled water. The absorbance (optical density) of the content was measured at $700 \mathrm{~nm}$ using a spectrophotometer (MRS Spectro UV- 
11) after allowing the reaction to occur for 10 mins. Ferric reducing power is a measure of absorbance in a reaction and the higher absorbance indicates the higher the reducing power of an extract or pure compound (Saeed et al., 2012).

\subsection{Statistical analysis}

All determinations were performed in triplicates $(n=$ 3 ) and the results are expressed as mean \pm SD. Data analysis was performed using SPSS 17.0 application software by means of two-way analysis of variance (ANOVA). The means were considered statistically significant when $\mathrm{p} \leq 0.05$.

\section{Results and discussion}

A total of six extracts viz. B. salviifolia chloroform leaves extract (1), $B$. salviifolia ethyl acetate leaves extract (2), B. salviifolia methanolic leaves extract (3), B. salviifolia chloroform stem bark extract (4), B. salviifolia ethyl acetate stem bark extract (5) and B. salviifolia methanolic stem bark extract (6) were prepared. These six extracts (1-6) were subjected to phytochemical analysis and the results are summarized in Table 1. Extract 1 showed the presence of phenolics, flavonoids, sterols and coumarins. Extract 2 showed the presence of alkaloids, phenolics, terpenoids, flavonoids, sterols, tannins, phlobatannins, quinones and reducing sugars. Extract 3 exhibited the presence of phenolics, terpenoids, flavonoids, sterols, saponins, tannins, quinones, reducing sugars and coumarins. Extract 4 showed the presence of alkaloids, phenolics, terpenoids, flavonoids and sterols. Extract 5 exhibited the presence of alkaloids, phenolics, terpenoids, sterols, tannins, phlobatannins, quinones, reducing sugars and coumarins. Extract 6 showed the presence of phenolics, terpenoids, flavonoids, sterols, saponins, tannins and reducing sugars (Table 1).

Table 1. Phytochemical screening of various extracts from leaves and stem bark of Buddleja salviifolia

\begin{tabular}{lllllll}
\hline \multirow{2}{*}{ Phytoconstituent } & \multicolumn{7}{c}{ Extracts } \\
\cline { 2 - 6 } & 1 & 2 & 3 & 4 & 5 & 6 \\
\hline Alkaloids & - & + & - & + & + & - \\
Phenolics & + & + & + & + & + & + \\
Terpenoids & - & + & + & + & + & + \\
Flavonoids & + & + & + & + & - & + \\
Sterols & + & + & + & + & + & + \\
Saponins & - & - & + & - & - & + \\
Tannins & - & + & + & - & + & + \\
Phlobatannins & - & + & - & - & + & - \\
Quinones & - & + & + & - & + & - \\
Reducing sugars & - & + & + & - & + & + \\
Coumarins & + & - & + & - & + & - \\
\hline
\end{tabular}

$(+)$ and $(-)$ signs indicate the presence and absence of the phytoconstituent, respectively.
The plant-derived secondary metabolites such as flavonoids and phenolics have ideal structural characteristics for free radical scavenging activity (Amarowicz et al., 2004). They have an aromatic ring bearing one or more hydroxyl groups (Tungmunnithum et al., 2018). These hydroxyl groups have the ability to donate hydrogen atoms to deactivate free radicals (Amarowicz et al., 2004). In phenolics, the number of hydroxyl groups contributes directly to the potency of antioxidant activity (Bendary et al., 2013). In flavonoids, however, the potency of antioxidant activity depends not only on the number of free hydroxyl groups but also on their position on the flavonoid skeleton (Panche et al., 2016). TFC and TPC of 1-6 are summarized in Table 2. Quercetin and gallic acid served as standards for TFC and TPC, respectively and their calibration curves are shown in Figures 1 and 2, respectively. The TFC of 1-6 was found to be $30.76 \pm 1.15,24.32 \pm 0.62,19.93 \pm 0.24$, $16.92 \pm 0.70,13.99 \pm 0.66$ and $11.36 \pm 0.98 \mathrm{mg}$ QE/g DW, respectively. This result indicated that 1 exhibited higher TFC relative to the other two leaf extracts viz. 2 and 3. Similarly, 4 showed higher TFC relative to the other two stem bark extracts viz. 5 and 6. Additionally, this result also revealed the fact that chloroform was found to be suitable for the extraction of flavonoids from plant materials (Pandey and Tripathi, 2014). The TPC of 1-6 was found to be $175.00 \pm 0.41, \quad 392.77 \pm 0.44$, $465.27 \pm 2.65, \quad 182.44 \pm 0.51, \quad 318.02 \pm 1.01 \quad$ and $281.93 \pm 0.12 \mathrm{mg} \mathrm{GAE} / \mathrm{g}$ DW, respectively. Extract 3 exhibited a higher TPC relative to the other two (1 and 2) leaf extracts. Similarly, 5 exhibited a higher TPC relative

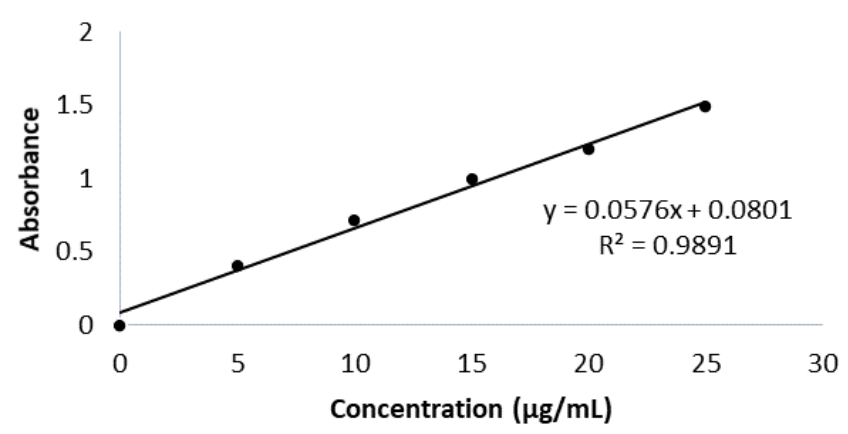

Figure 1. The calibration curve of quercetin (used to estimate TFC)

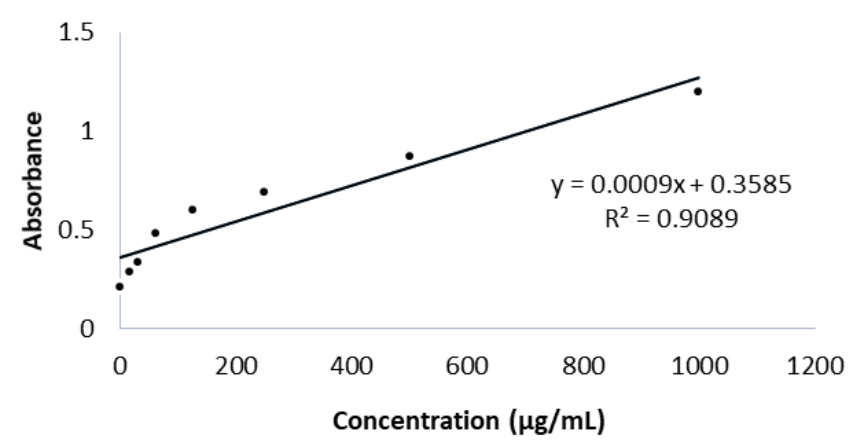

Figure 2. The calibration curve of gallic acid (used to estimate TPC) 
Table 2. Total flavonoid contents (TFC) and total phenolic contents (TPC) of various extracts from leaves and stem bark of Buddleja salviifolia

\begin{tabular}{cccccccc}
\hline \multirow{2}{*}{ Extracts } & TFC & TPC & \multicolumn{4}{c}{ Ferric reducing power/concentration of extracts in $\mu \mathrm{g} / \mathrm{mL}$} \\
\cline { 5 - 8 } & $(\mathrm{mg} \mathrm{QE} / \mathrm{g})$ & $(\mathrm{mg} \mathrm{GAE} / \mathrm{g})$ & 12.5 & 25 & 50 & 100 & 200 \\
\hline 1 & $30.76 \pm 1.15$ & $175.00 \pm 0.41$ & $0.179 \pm 0.03$ & $0.184 \pm 0.00$ & $0.186 \pm 0.01$ & $0.199 \pm 0.01$ & $0.217 \pm 0.05$ \\
2 & $24.32 \pm 0.62$ & $392.77 \pm 0.44$ & $0.207 \pm 0.01$ & $0.212 \pm 0.08$ & $0.244 \pm 0.01$ & $0.292 \pm 0.05$ & $0.387 \pm 0.02$ \\
3 & $19.93 \pm 0.24$ & $465.27 \pm 2.65$ & $0.200 \pm 0.01$ & $0.270 \pm 0.00$ & $0.346 \pm 0.07$ & $0.491 \pm 0.09$ & $0.656 \pm 0.00$ \\
4 & $16.92 \pm 0.70$ & $182.44 \pm 0.51$ & $0.189 \pm 0.03$ & $0.192 \pm 0.01$ & $0.217 \pm 0.04$ & $0.244 \pm 0.00$ & $0.278 \pm 0.00$ \\
5 & $13.99 \pm 0.66$ & $318.02 \pm 1.01$ & $0.204 \pm 0.06$ & $0.222 \pm 0.07$ & $0.266 \pm 0.00$ & $0.313 \pm 0.02$ & $0.407 \pm 0.01$ \\
6 & $11.36 \pm 0.98$ & $281.93 \pm 0.12$ & $0.229 \pm 0.01$ & $0.285 \pm 0.02$ & $0.291 \pm 0.00$ & $0.362 \pm 0.00$ & $0.512 \pm 0.02$ \\
Asc. acid & N/A & N/A & $0.437 \pm 0.09$ & $0.554 \pm 0.01$ & $0.663 \pm 0.11$ & $0.812 \pm 0.01$ & $0.992 \pm 0.09$ \\
\hline
\end{tabular}

Values are expressed as mean \pm SD of triplicates $(n=3)$. TFC: Total flavonoid contents, TPC: Total phenolic contents. Asc. Acid: ascorbic acid, N/A: Not applicable.

to the other two (4 and 6) stem bark extracts.

The ability of flavonoids and phenolics to transform a $\mathrm{Fe}^{3+}$ (ferricyanide complex) to a $\mathrm{Fe}^{2+}$ (ferrouscyanide complex) acts as a potential indicator for the antioxidant activity (Meir et al., 1995). In other words, the ferric salt is reduced to ferrous salt and the flavonoids and phenolics are oxidized. The absorbance (optical density) for this oxidation process could be measured which is a measure of the antioxidant capacity of flavonoids and phenolics. The ferric reducing power of 1-6 and the positive control (ascorbic acid) have a linear relation with concentrations (refer to Table 2 and Figures 1 and 2 ). The ferric reducing power of 1-3, 4-6 and ascorbic acid were found to be in the ranges of $0.179 \pm 0.03$ $0.656 \pm 0.00, \quad 0.189 \pm 0.03-0.512 \pm 0.02$ and $0.437 \pm 0.09$ $0.992 \pm 0.09$, respectively (refer to Table 2). Among leaf extracts, 3 showed the highest ferric reducing power of $0.656 \pm 0.00$ at a concentration of $200 \mu \mathrm{g} / \mathrm{mL}$ followed by $2(0.387 \pm 0.02)$ and $1(0.217 \pm 0.05)$, respectively. Among stem bark extracts, 6 exhibited the highest ferric reducing power of $0.512 \pm 0.02$ at a concentration of 200 $\mu \mathrm{g} / \mathrm{mL}$ followed by $5(0.407 \pm 0.01)$ and $4(0.278 \pm 0.00)$.
However, all three leaf extracts (1-3) and all three stem bark extracts (4-6) showed lower ferric reducing power compared to a positive control (refer to Table 2 and Figure 3).

This is the first report on the preliminary phytochemical screening of various extracts from $B$. salviifolia.

However, terpenoids have previously been reported from other species of the Buddleja genus (Houghton et al., 2003). In a previous report, the TFC of dichloromethane/methanol (1:1) and water extracts from whole plants of $B$. salviifolia have been reported as $23.95 \pm 0.11$ and $12.11 \pm 0.26 \mathrm{mg} \mathrm{QE} / \mathrm{g}$ DW (milligrams of quercetin equivalents per gram of dry sample), respectively (Adewusi et al., 2011). Similarly, the TPC of these two extracts has been reported as $169.66 \pm 0.33$ and $77.92 \pm 0.91 \mathrm{mg} \mathrm{TAE} / \mathrm{g} \mathrm{DW}$ (milligrams of tannic acid equivalents per gram of dry sample), respectively (Adewusi et al., 2011). In the present study, the TFC and TPC of various extracts from leaves and stem bark of $B$. salviifolia were found to be in the range of $11.36 \pm 0.98$ to

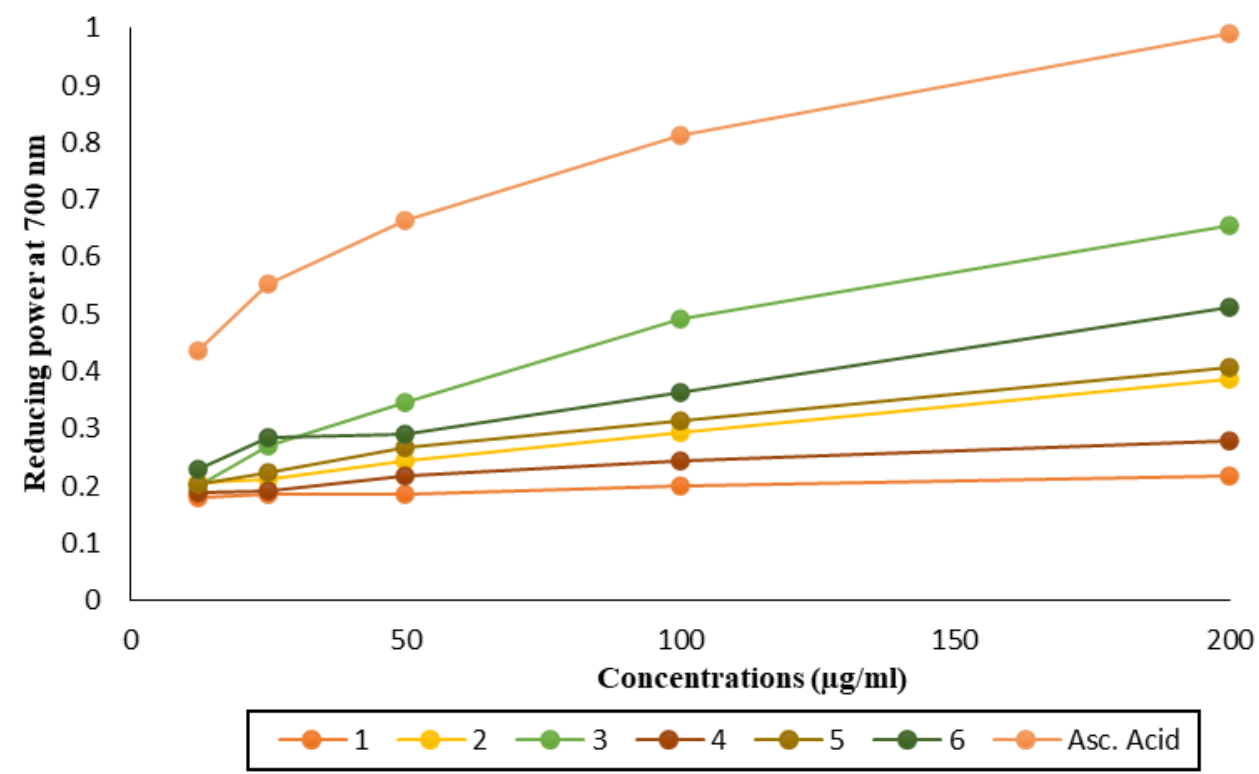

Figure 3. Reducing power of various extracts from leaves and stem bark of $B$. salviifolia at various concentrations. Asc. acid = ascorbic acid. 
$30.76 \pm 1.15 \mathrm{mg} \quad \mathrm{QE} / \mathrm{g} \quad \mathrm{DW}$ and $175.00 \pm 0.41$ to $465.27 \pm 2.65 \mathrm{mg}$ GAE/g DW, respectively. The discrepancy in the TFC and TPC in our study and the previous report may be due to the polarity of different solvents and plant parts used for the extraction of active components. Extracts 2, 3, 5 and 6 showed significant ferric reducing power due to the presence of tannins (refer to Table 1). Tannins have been reported to have ferric reducing power (Okuda, 2005). Various extracts from $B$. salviifolia have previously been reported to have DPPH radical scavenging activity (Matamane et al. 2019), which could be due to the presence of phytochemicals such as polyphenols, phenolics and flavonoids. These phytochemicals have been reported as important classes of natural antioxidants (Array et al., 2019; Rodrigues et al., 2019).

\section{Conclusion}

The phytochemical profiles, TFC, TPC and ferric reducing power of chloroform, ethyl acetate and methanolic extracts from leaves and stem bark of $B$. salviifolia were studied. The presence of alkaloids, tannins, phlobatannins, saponins, sterols, flavonoids, coumarins, phenolics, terpenoids, quinones and reducing sugars was identified from these extracts. The TFC of these extracts was found to be in the range of $11.36 \pm 0.98$ to $30.76 \pm 1.15 \mathrm{mg} \mathrm{QE} / \mathrm{g} \mathrm{DW}$, respectively. The TPC of these extracts was found to be in the range of $175.00 \pm 0.41$ to $465.27 \pm 2.65 \mathrm{mg} \mathrm{GAE} / \mathrm{g} \mathrm{DW}$, respectively. Additionally, these extracts showed a weak to moderate ferric reducing power compared to ascorbic acid. Further studies are required to commercialize products from this plant.

\section{Conflict of interests}

The authors declare no conflicts of interest.

\section{Acknowledgements}

The authors thank the National University of Lesotho for the overall support.

\section{References}

Adewusi, E., Moodley, N. and Steenkamp, V. (2011). Antioxidant and acetylcholinesterase inhibitory activity of selected southern African medicinal plants. South African Journal of Botany, 77(3), 638644. https://doi.org/10.1016/j.sajb.2010.12.009

Amarowicz, R., Pegg, R., Rahimi-Moghaddam, P., Barl, B. and Weil, J. (2004). Free-radical scavenging capacity and antioxidant activity of selected plant species from the Canadian prairies. Food Chemistry, 84(4), 551-562. https://doi.org/10.1016/S0308-8146

\section{(03)00278-4}

Array, E., Tonfack, D., Kinge, K., Kinge, E. and Womeni, H. (2019). Effect of different extraction solvents on the phenolic content and antioxidant activity of tumeric (Curcuma longa) from south-west region, Cameroon. Food Research, 3(1), 86-90. https://doi.org/10.26656/fr.2017.3(1).227

Bendary, E., Francis, R.R., Ali, H.M.G., Sarwat, M.I. and El Hady, S. (2013). Antioxidant and structureactivity relationships (SARs) of some phenolic and anilines compounds. Annals of Agricultural Sciences, 58(2), 173-181. https://doi.org/10.1016/ j.aoas.2013.07.002

Drummond, R. (1981). Trees of Southern Africa. Cape Town, South Africe: Tien Wah Press (Pty) Ltd.

Fejes, S., Blazovics, A., Lugasi, A., Lamberkovic, E., Petri, G. and Kery, A. (2000). In vitro antioxidant activity of Anthriscus cerefolium L. (Hoffm.) extracts. Journal of Ethnopharmacology, 69(3), 259265. https://doi.org/10.1016/S0378-8741(99)00171-3

Houghton, P., Mensiah, A., Lessa, N. and Hong, L. (2003). Terpenoids in Buddleja: relevance to chemosystematics, chemical ecology and biological activity. Phytochemistry, 64(2), 385-393. https:// doi.org/10.1016/S0031-9422(03)00264-4

Joshi, S., Parkhe, G., Aqueel, N., Dixit, N. and Jain, D. (2019). Estimation of total phenolic, total flavonoids and total protein content of hydroalcoholic extract of Anacyclus pyrethrum. Pharmacology Online, 2, 2733.

Kokate, C. (1994). Practical pharmacognosy. Delhi, India: Vallabh Prakashan.

Kose, L., Moteetee, A. and Van Vuuren, S. (2015). Ethnobotanical survey of medicinal plants used in the Maseru district. Journal of Ethnopharmacology, 170, 184-200. https://doi.org/10.1016/ j.jep.2015.04.047

Matamane, R., Pillai, M. and Magama, S. (2019). DPPH radical scavenging activity of extracts from Buddleja salviifolia. Pharmacology Online, 2, 233-240.

Meir, S., Kanner, J., Akiri, B. and Philosoph-Hadas, S. (1995). Determination and involvement of aqueous reducing compounds in oxidative defense systems of various senescing leaves. Journal of Agricultural and Food Chemistry, 43, 1813-1819. https:// doi.org/10.1021/jf00055a012

Nwaoguikpe, R., Ujowundo, C. and Emejulu, A. (2014). The antioxidant and free radical scavenging Effects of extracts of seed of some neglected legumes of south-east Nigeria. Scholars Academic Journal of Bioscience, 2(1), 51-59.

Okuda, T. (2005). Systematics and health effects of 
chemically distinct tannins in medicinal plants. Phytochemistry, 66(17), 2012-2031. https:// doi.org/10.1016/j.phytochem.2005.04.023

Palmer, E. (1997). A field guide to the trees of Southern Africa. Great Britian: Glasgow, UK: William Collins sons and Co Ltd.

Panche, A.N., Diwan, A.D. and Chandra, S.R. (2016). Flavonoids: An overview. Journal of Nutritional Sciences, 5, e47. https://doi.org/10.1017/jns.2016.41

Pandey, A. and Tripathi, S. (2013). Concept of standardization, extraction and pre-phytochemical screening strategies for herbal drug. Journal of Pharmacognosy and Phytochemistry, 2(5), 115-119.

Pendota, S., Aderogba, M., Ndhlala, A. and Van Staden, J. (2013). Antimicrobial and acetylcholinesterase inhibitory activity of Buddleja salviifolia (L.) Lam. leaf extracts and isolated compounds. Journal of Ethnopharmacology, 148(2), 515-520. https:// doi.org/10.1016/j.jep.2013.04.047

Pillai, M., Matamane, R. and Mekbib, S. (2019). Antimicrobial actiivities of extracts from leaves and stem bark of Buddleja salviifolia. Food Research, 3 (6), 761-767. https://doi.org/10.26656/fr.2017.3 (6). 195

Ream, J. (2006). Production and invasion of Butterfly Bush (Buddleja davidii) in Oregon. Oregon: USA: Oregon State University.

Rodrigues, R., Lima, A., Melo, A.C.F.L. and Trindade, R. (2019). Physicochemical characterization, bioactive compounds and in vitro antioxidant activities of commercial integral grape juice. International Food Research Journal, 26(2), 469479.

Saeed, N., Khan, M. and Shabbir, M. (2012). Antioxidant activity, total phenolic and flavonoid contents of whole plant extracts Torris leptophylla $\mathrm{L}$. BMC Complementary and Alternative medicine, 12, 221. https://doi.org/10.1186/1472-6882-12-221

Soni, A. and Sheetal, S. (2013). Phytochemical analysis and free radical scavenging potential of herbal and medicinal plant extracts. Journal of Pharmacognosy, 2(4), 22-29.

Tank, D., Beardsley, P., Kelcher, S. and Olmsted, R. (2006). Review of the systematics of Scrophulariaceae s.l. and their current disposition. Australian Systematics Botany, 19(4), 290-299. https://doi.org/10.1071/SB05009

Tiwari, P., Kumar, B.K., Kaur, G. and Kaur, H. (2011). Phytochemical screening and extraction: A review. Internationale Pharmaceutica Scientia, 1(1), 98-106.

Trease, G. and Evans, C. (1984). Pharmacognosy. 12th ed. London: Billiere Tinda.
Trease, G. and Evans, C. (2002). Textbook of pharmacognosy. 15th ed. London: Sanders Publishers.

Tungmunnithum, D., Thongboonyou, A., Pholboon, A. and Yangsabai, A. (2018). Flavonoids and other phenolic compounds from medicinal plants for pharmaceutical and medical aspects: An overview. Medicines, 5(3), 93. https://doi.org/10.3390/ medicines5030093

Uddin, G., Feroz, S., Ali, J. and Rauf, A. (2014). Antimicrobial activity of Pterospernum acerifolium (leaf petiole). Wupecker Journal of Agriculture Resource, 3, 58-65.

Van Laere, K., Van Huylenbroeck, J. and Van Bockstaele, E. (2011). Introgression of yellow of flower colour in Buddleja davidii by means of polyploidisation and interspecific hybridization. Horticulture Science, 38(2), 96-106. https:// doi.org/10.17221/61/2011-HORTSCI

Van Wyk, B. and Van Wyk, P. (1997). Field of trees of Southern Africa featuring more than 1000 species. Struik Publishers. 